\title{
PREDIKSI PENYAKIT TUBERCULOSIS PARU (TB PARU) MENGGUNAKAN METODE LEARNING VEKTOR QUANTIZATION (LVQ)
}

\author{
A. W. Rahmadani ${ }^{1}$, A. I. Jaya ${ }^{2}$, dan N. Nacong ${ }^{3}$ \\ 1,2,3Program Studi Matematika Jurusan Matematika FMIPA Universitas Tadulako \\ Jalan Soekarno-Hatta Km. 09 Tondo, Palu 94118, Indonesia. \\ 1ayuwulanramadhani02@gmail.com, 2jayaindraagus@gmail.com,3nasrianacong@gmail.com
}

\begin{abstract}
Tuberculosis pulmonary (TB pulmonary) is a contagious disease that attacks the lungs that can spread through the air when a person active TB cough, sneeze or talk. This study aims to predict Tuberculosis pulmonary disease using Learning Vector quantization based on data from the medical records of the health centers kamonji, Palu city. The study was conducted using 8 TB pulmonary disease risk factors which are age, gender, fever, long cough, cough, chest pain, shortness of breath, and decreased body weight. Classification is done by using 100 data consisting of 80 training data and 20 testing data. Results of the study showed that tested all the data correctly with rank of accuracy is $100 \%$.
\end{abstract}

Keywords : Accuracy, Learning Vector Quantization (LVQ), Disease Tuberculosis Pulmonary.

\section{ABSTRAK}

Tuberculosis Paru (TB Paru) adalah penyakit menular yang menyerang paru-paru yang dapat menular melalui udara waktu seseorang TB aktif batuk, bersin atau bicara. Penelitian ini bertujuan untuk memprediksi penyakit Tuberculosis Paru dengan menggunakan Learning Vector Quantization berdasarkan data rekam medis puskesmas kamonji kota palu. Penelitian dilakukan dengan menggunakan 8 faktor resiko penyakit TB Paru yaitu usia, jenis kelamin, deman, lama batuk, jenis batuk, nyeri dada, sesak nafas, dan berat badan menurun. Klasifikasi dilakukan dengan menggunakan 100 data yang terdiri dari 80 data pelatihan dan 20 data pengujian. Hasil penelitian juga menunjukan seluruh data yang diuji benar dengan tingat akurasi adalah $100 \%$

Kata Kunci : Akurasi, Learning Vector Quantization (LVQ), Penyakit Tuberculosis Paru. 


\section{PENDAHULUAN}

Tuberculosis Paru (TB Paru) adalah penyakit menular yang menyerang paru-paru, penyakit ini disebabkan oleh kuman dari kelompok Mycobacterium. Menurut World Health Organization sejak tahun 2010 hingga 2011, di Indonesia tercatat 430.000 penderita TB paru dengan korban meninggal sejumlah 61.000. Jumlah ini lebih kecil dibandingkan kejadian tahun 2009 yang mencapai 528.063 penderita TB paru dengan 91.369 orang meninggal (WHO, 2012).

Tuberkulosis adalah suatu penyakit infeksi yang disebabkan bakteri berbentuk batang (basil) yang dikenal dengan nama Mycobacterium tuberkulosis. Penularan penyakit ini melalui perantaraan ludah atau dahak penderita yang mengandung basil tuberkulosis paru. Pada waktu penderita batuk butir-butir air ludah beterbangan diudara dan terhisap oleh orang yang sehat dan masuk kedalam parunya yang kemudian menyebabkan penyakit tuberkulosis paru.

Menurut Padila (2013), gejala-gejala TB terdiri dari demam, batuk, nyeri dada, sesak nafas, dahak disertai darah, berat badan menurun, dan berkeringat di malam hari. Sedangkan faktor resiko antara lain merokok, riwayat penyakit diabetes militis dan HIV (Kemenkes, 2014).

Penanganan penyakit TB Paru dilakukan selama 6-9 bulan dengan paling sedikit 3 macam obat. Masyarakat masih mengganggap batuk selama berbulan-bulan merupakan batuk biasa, Apabila dicermati batuk dalam jangka waktu yang panjang merupakan salah satu gejala yang ditimbulkan oleh penyakit TB Paru. Umumnya masyarakat baru memeriksakan penyakitnya ketika sudah parah, yang dilakukan melalui pemeriksaan fisik di daerah paru atau dada dan pemeriksan tambahan berupa foto rontgen dada serta tes laboratorium. Penanganan yang lambat berbahaya jika tidak ditanggulangi dengan benar, karena kuman yang masuk ke saluran napas dapat menyebar ke seluruh tubuh seperti selaput otak, hati, ginjal, tulang.

Penelitian mengenai pendektesian penyakit TB telah banyak di kembangkan. Ratnaningtyas (2013) melakukan penelitian kasus TB dengan menggunakan metode backpropagation. Pada tahun (2016) Novia Dwi Asmaningtias, melakukan penelitian dengan menggunakan metode Learning Vector Quantization yang melibatkan 12 faktor resiko yaitu demam, malaise, badan lemah, nafsu makan menurun, berat badan menurun, batuk selama lebih dari 3 minggu, dahar berwarna kuning/hijau, batuk darah, keringat malam hari, mengi, sesak nafas, dan nyeri dada. dengan akurasi $=91,11 \%$.

Dalam penelitian ini, akan dilakukan prediksi seseorang terkena Penyakit TB Paru dengan mengimplementasikan algoritma Learning Vector Quantization, dan melibatkan 8 faktor resiko yaitu usia, jenis kelamin, lama batuk, jenis batuk, sesak nafas, nyeri dada, demam berat badan menurun. analisa data dilakukan dengan mengolah data rekam medis puskesmas kamonji berupa nilai ratarata pasien TB Paru dan bukan TB. Learning Vector Quantization (LVQ) adalah suatu metode untuk melakukan pembelajaran pada lapisan kompetitif yang terawasi. Suatu lapisan kompetitif akan secara otomatis belajar untuk mengklasifikasikan vektor vektor input. Kelas-kelas yang didapatkan 
sebagai hasil dari lapisan kompetitif ini hanya tergantung pada jarak antara vektor vektor input. Jika 2 vektor input mendekati sama, maka lapisan kompetitif akan meletakkan kedua vektor input tersebut ke dalam kelas yang sama. Learning Vector Quantization dimanfaatkan dalam sistem untuk mencari pola pasien terkena penyakit TB Paru dengan variabel yang didapat dari faktor dan gejala yang di timbulkan oleh penyakit TB.

\section{METODE PENELITIAN}

Penelitian ini merupakan tinjauan matematis terhadap proses pengklasifikasian penyakit TB Paru. Proses pengolahan data dilakukan dengan mengkonversi data rekam medis puskesmas kamonji.

\subsection{Jaringan Saraf Tiruan}

Jaringan syaraf adalah merupakan salah satu representasi buatan dari otak manusia yang selalu mencoba untuk mensimulasikan proses pembelajaran pada otak manusia tersebut. Istilah buatan disini digunakan karena jaringan syaraf ini diimplementasikan dengan menggunakan program komputer yang mampu menyelesaikan sejumlah proses perhitungan selama proses pembelajaran. Struktur JST terdiri dari neuron dan bobot. Neuron merupakan bagian penerima informasi dan meneruskan hasil olahan informasi kekuatan informasi yang masuk ke neuron ditandai dengan adanya bobot. Secara umum ada 2 proses pada JST yaitu proses training dan testing. Pada proses training, JST diberikan pengetahuan yang berupa pola-pola data sebagai masukan untuk dilatih dan menghasilkan sebuah model JST. Pada tahap testing, JST akan mencoba mengenali pola-pola masukan yang diujikan untuk kemudian dicocokkan dengan hasil proses pelatihan.

\subsection{Learning Vector Quantization}

Learning Vector Quantization (LVQ) merupakan jaringan lapisan tunggal (single-layer net) di mana lapisan masukan terkoneksi secara langsung dengan setiap neuron pada keluaran. Koneksi antar neuron tersebut dihubungkan dengan bobot/weight. Neuron-neuron keluaran pada $L V Q$ menyatakan suatu kelas atau kategori tertentu. Bobot merupakan nilai matematis dari koneksi yang mentransfer data dari satu lapisan ke lapisan lainnya, yang berfungsi untuk mengatur jaringan sehingga dapat menghasilkan output yang diinginkan. Bobot pada LVQ sangat penting, karena dengan bobot ini input dapat melakukan pembelajaran dalam mengenali suatu pola. Vektor bobot berfungsi untuk menghubungkan setiap neuron pada lapisan input dengan masing-masing neuron pada lapisan output (Kusmadewi, 2003). 
Algoritma Learning Vector Quantization (LVQ) adalah sebagai berikut :

1. Siapakan data learning $x(m, n)$ dengan $\operatorname{target} T(1, n)$

2. Inisialisasi bobot ( $w$ ), maksimum epoh (Max Epoh), errorminimum yang diharapkan (Eps), learning rate $(\alpha)$. Max epoh yang digunakan untuk menentukan batas ambang.

3. Melakukan proses sebagai berikut selama (epoh<maksEpoh) atau $(\alpha>e p s)$.

Epoh $=$ epoh +1.

Kerjakan untuk $i=1$ sampai $n$

4. Carilah $j$ sehingga minimum $\left\|x-w_{j}\right\|$

5. Perbaharui $w_{j}$ sebagai berikut :

Jika $T=C_{j}$ maka $w_{j}($ baru $)=w_{j}($ lama $)+\alpha\left(x-w_{j}(\right.$ lama $\left.)\right)$ jika $T \neq C_{j}$ maka $w_{j}($ baru $)=w_{j}($ lama $)-\alpha\left(x-w_{j}(\right.$ lama $\left.)\right)$

6. Kurangi laju pelatihan $\alpha$ (baru) $=\alpha$ (lama) $-0,1 * \alpha$ (lama)

7. Kembali ke langkah ke-3, ke-4 dan ke-5 jika (epoh< maksEpoh) atau $(\alpha>$ eps) tidak terpenuhi, selesai.

dimana,

$x \quad=$ training vector $\left(x_{1}, x_{2}, \ldots x_{n}\right)$

$T \quad=$ kelas dari training vector

$w_{j} \quad=$ bobot vektor untuk luaran ke- $j$

$C_{j} \quad=$ kategori atau kelas yang dihasilkan dari luaran ke- $j$

$\left\|x-w_{j}\right\|=$ Jarak Euclidean antar vektor masukan dan bobot vektor ke- $j$

$\alpha \quad=$ learning rate

$i \quad=$ node input

$j \quad=$ node output

Setelah dilakukan pelatihan, akan diperoleh bobot akhir $(w)$. Bobot-bobot ini nantinya akan digunakan untuk melakukan klasifikasi terhadap data baru. (Hariri dan Fajar, 2013).

\subsection{Perancangan Sistem}

Penelitian ini akan memprediksi TB Paru atau non TB untuk Keluaran (output) adalah : non TB bernilai 1, dan TB Paru bernilai 2. Berikut ini hal yang diperlukan dalam pembuatan sistem, yaitu :

a. Variabel dan transformasinya

Berdasarkan gejala klinisnya, penyakit tuberculosis secara umum dapat diidentifikasi dari 8 faktor resiko tersebut, diantaranya adalah , Usia $\left(x_{1}\right)$, Jenis Kelamin $\left(x_{2}\right)$, Lama Batuk $\left(x_{3}\right)$, Jenis Batuk $\left(x_{4}\right)$, Sesak Nafas $\left(x_{5}\right)$, Nyeri Dada $\left(x_{6}\right)$, Demam $\left(x_{7}\right)$, Berat Badan Menurun $\left(x_{8}\right)$, Agar dapat diolah menggunakan metode Learning Vector Quantization, variabel-variabel tersebut harus ditransformasikan menjadi bentuk yang sesuai dengan keperluan. Transformasi masing-masing variabel dapat dilihat dalam Tabel 1. 
Tabel 1 : Variabel dan transformasinya

\begin{tabular}{|l|l|c|}
\hline \multicolumn{1}{|c|}{ Atribut } & \multicolumn{1}{|c|}{ Kategori } & Nilai Konversi \\
\hline \multirow{2}{*}{ Usia } & "remaja \& dewasa "(17 - 45 Tahun) & 0 \\
\hline \multirow{2}{*}{ Jenis Kelamin } & "lansia" (> 46 Tahun) & 1 \\
\hline \multirow{2}{*}{ Lama batuk } & Laki - Laki & 0 \\
\cline { 2 - 3 } & Perempuan & 1 \\
\hline \multirow{2}{*}{ Jenis Batuk } & 1 Minggu - 3 Minggu & 1 \\
\cline { 2 - 3 } & $>1$ Bulan & 0 \\
\hline \multirow{2}{*}{ Sesak Nafas } & Batuk berdahak & 1 \\
\cline { 2 - 3 } & Batuk berdarah & 0 \\
\hline \multirow{2}{*}{ Nyeri Dada } & Tidak Sesak Nafas & 1 \\
\cline { 2 - 3 } & Sesak Nafas & 1 \\
\hline \multirow{2}{*}{ Demam } & Tidak Sakit Dada & 0 \\
\cline { 2 - 3 } & Sakit Dada Setiap Batuk & 1 \\
\hline \multirow{2}{*}{$\begin{array}{l}\text { Berat Badan } \\
\text { Menurun }\end{array}$} & Tidak Demam & 1 \\
\cline { 2 - 3 } & Demam & 0 \\
\cline { 2 - 3 } & Tidak & 1 \\
\cline { 2 - 3 } & Ya & 1 \\
\hline
\end{tabular}

b. Pelatihan

Pelatihan dilakukan menggunakan jaringan LVQ. Berdasarkan jumlah keluaran maka jumlah kelas yang dipakai pada metode ini sebanyak 2 yaitu Non TB dan TB Paru. Untuk data pelatihan menggunakan $80 \%$ dari 100 data. Langkah yang dikerjakan yaitu menentukan data pelatihan, tetapkan nilai parameter minimum $\alpha$ dan penurunan $\alpha$, inisialisasi klaster awal, mencari jarak vektor, tentukan klaster data dengan memilih jarak vektor yang minimum, selama $(\alpha \geq \operatorname{Min} \alpha)$, hitung nilai bobot dan perubahan nilai $\alpha$, simpan bobot akhir.

c. Pengujian

Setelah dihasilkan bobot akhir, tahap selanjutnya adalah pengujian untuk data pengujian menggunakan $20 \%$. langkahnya adalah pilih bobot akhir, pilih data yang akan diuji, mencari jarak vektor dengan memilih jarak vektor yang minimum.

\subsection{Penetapan Output}

Pada penelitian ini output dibagi menjadi dua kelas yaitu Non TB dimisalkan 1 dan TB Paru dimisalkan 2. Pembagian kelas tersebut berdasarkan jumlah keluaran yang diharapkan yaitu Non TB atau TB Paru. 


\subsection{Pembentukan Arsitektur Jaringan Syaraf Tiruan}

Dalam arsitektur jaringan ini dibentuk pola-pola hubungan antara neuron. Neuronneuron ini kemudian akan dihubungkan dngan bobot. Adapun arsitektur jaringan yang digunakan dalam penelitian ini adalah sebagai berikut :

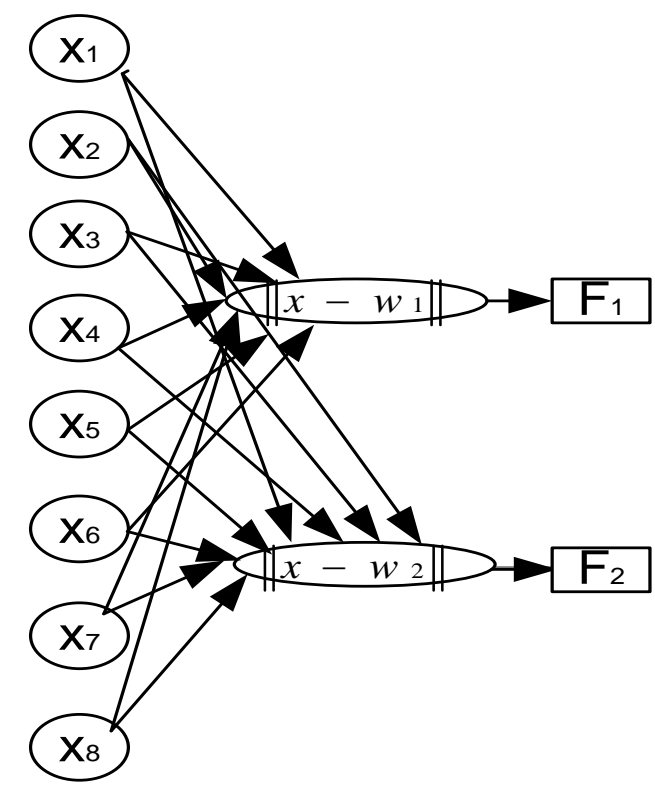

Gambar 1 : Arsitektur Jaringan Syaraf Tiruan

\section{HASIL DAN PEMBAHASAN}

Data penelitian ini diambil dari puskesmas kamonji palu. Data tersebut adalah data pasien yg digunakan untuk memprediksi penyakit TB Paru yang terdiri dari 8 parameter, yaitu usia, jenis kelamin, lama batuk, jenis batuk, sesak nafas, nyeri dada, demam berat badan menurun.

Data dari 8 parameter penyakit TB tersebut sebanyak 100 data yang diambil dari pasien TB Paru. Data dibagi ke dalam dua bagian, satu bagian digunakan untuk proses training dan satu bagian digunakan untuk data testing. Data training digunakan untuk membangun model, sedangkan data testing digunakan untuk mengukur akurasi. Prediksi penyakit TB Paru ini menggunakan $80 \%$ untuk data training dan $20 \%$ data testing. Sebelum data training dan data testing diolah menggunakan Learning Vector Quantization, data tersebut perlu ditransformasi terlebih dahulu.

Selanjutnya metode Learning Vector Quantization diterapkan untuk mengklasifikasikan penyakit TB Paru ke dalam salah satu kelas yaitu kelas TB Paru dan Non TB.

Adapun parameter yang digunakan pada proses uji coba pelatihan jaringan LVQ diantaranya variasi laju pelatihan $\alpha$ yang digunakan yaitu $(0,1 ; 0,5 ; 0,7 ; 0,9)$, nilai variasi pengurangan laju pelatihan $(\operatorname{Dec} \alpha)$ yaitu $(0,01 ; 0,001 ; 0,0001)$. Maka akan didapatkan bobot akhir pelatihan sebagai 
bobot terbaik, yang selanjutnya akan digunakan pada proses pengujian hasil bobot perubahan nilai $\alpha$ dan $\operatorname{dec} \alpha$. Selama proses pelatihan jaringan akan melakukan perubahan bobot dalam batas iterasi yang ditentukan selama nilai sedangkan perubahan pada nilai $\alpha$ jaringan akan mengalami penurunan nilai $\alpha$ setiap kali epoch.

Tabel 2 : Perandingan Hasil Pengujian

\begin{tabular}{|c|c|c|}
\hline $\operatorname{Dec} \alpha$ & $\alpha$ & $\begin{array}{c}\text { Tingkat Akurasi } \\
(\%)\end{array}$ \\
\hline \multirow[t]{4}{*}{0,01} & 0,1 & $100 \%$ \\
\hline & 0,5 & $100 \%$ \\
\hline & 0,7 & $87 \%$ \\
\hline & 0,9 & $100 \%$ \\
\hline \multirow[t]{4}{*}{0,001} & 0,1 & $100 \%$ \\
\hline & 0,5 & $100 \%$ \\
\hline & 0,7 & $87,14 \%$ \\
\hline & 0,9 & $87,14 \%$ \\
\hline \multirow[t]{4}{*}{0,0001} & 0,1 & $100 \%$ \\
\hline & 0,5 & $94,87 \%$ \\
\hline & 0,7 & $87,18 \%$ \\
\hline & 0,9 & $87,18 \%$ \\
\hline
\end{tabular}

Setelah dilakukan proses pelatihan Berdasarkan Tabel 2. diatas hasil pengujian terbaik sebesar $100 \%$, Tingkat akurasi tertinggi ada dibeberapa variasi learning rate dan pembaruan laju pelatihan Dec $\alpha$. Maka parameter optimal pada penelitian ini adalah pada learning rate 0,1

Keberhasilan proses dapat dilihat pada Gambar 2. Gambar 2 tersebut memperlihatkan hasil grafik yang terjadi pada proses pengujian.

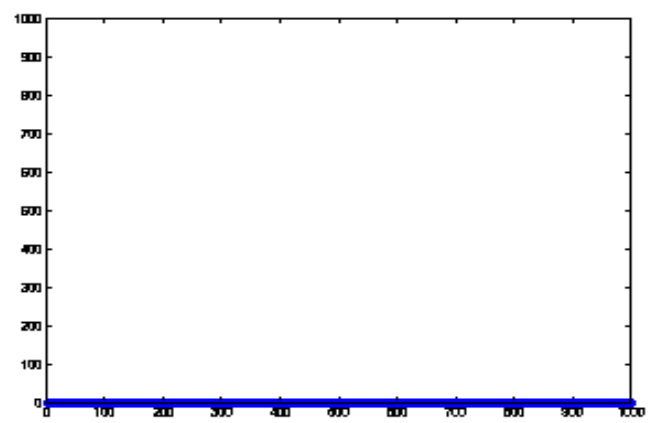

Gambar 2 : Nilai error Tuberculosisi Paru Dengan Learning Rate 0,1 


\section{KESIMPULAN}

Berdasarkan hasil dan pembahasan yang telah dilakukan, dapat ditarik kesimpilan bahwa Proses prediksi menggunakan jaringan syaraf tiruan yang dilakukan terhadap 100 data yang masingmasing di bagi menjadi 80 data pelatihan dan 20 data pengujian untuk prediksi penyakit tuberculosis Paru menghasilkan system yang dapat bekerja dengan baik. Tingkat akurasi Learning Vector Quantization pada penelitian ini mengenali $100 \%$ data sesuai target.

\section{DAFTAR PUSTAKA}

[1] Aditama, T, Y, Tuberkulosis, Pedoman Diagnosis, Perhimpunan Dokter Paru Indonesia p, $1,5,10,15,2005$, Jakarta.

[2] Depkes, R,I, Pedoman penanggulangan nasional TBC , 2011, Jakarta.

[3] Hariri dan Fajar Rohman, Implementasi Metode Learning Vektor Quantization Untuk Diagnosa Penyakit Diabetes Meliitus, 2013 Yogyakarta.

[4] Kementrian Kesehatan R,I, Direktorat Jenderal Pengendalian Penyakit dan Penyehatan Lingkungan, Pedoman Nasional Pengendalian Tuberculosis, Bebas Tuberculosis, 2014, Indonesia.

[5] Kusumadewi, S, Artificil Intelligence (Teknik dan Aplikasinya), Graha Ilmu, 2003, Yogyakarta.

[6] Novia Dwi Asmaningtias, Rancang Bangun Aplikasi Diagnosa Awal Tuberkulosis Menggunakan Metode Learning Vector Quantization, Universitas Airlangga, 2016.

[7] Padila, Asuhan Keperawatan Penyakit Dalam, Nusa Medika, 2013, Yogyakarta.

[8] Siang, J, J, Jaringan Syaraf Tiruan dan Pemrogramannya Menggunakan Matlab, Andi Offset, 2005, Yogyakarta. 